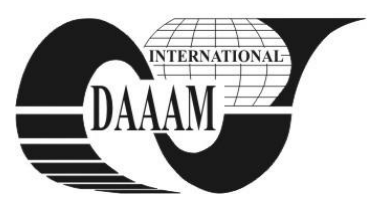

Annals of DAAAM for 2012 \& Proceedings of the 23rd International DAAAM Symposium, Volume 23, No.1, ISSN 2304-1382 ISBN 978-3-901509-91-9, CDROM version, Ed. B. Katalinic, Published by DAAAM International, Vienna, Austria, EU, 2012 Make Harmony between Technology and Nature, and Your Mind will Fly Free as a Bird Annals \& Proceedings of DAAAM International 2012

\title{
EXPERIMENTAL MEASUREMENTS OF FRICTION IN DESIGNING AXISYMMETRIC WORKPIECES OF LAMINATED WOOD
}

\author{
NEZIREVIC, E[krem]; HODZIC, A[tif] \& HODZIC, D[amir]
}

\begin{abstract}
This paper presents the procedure and the results of experimental measurements of friction forces, which arise as a result of the resistance to movement of veneer over curved contact surface of tool-shapers during the forming process of axisymmetric workpieces made from laminated wood. Friction forces are measured in three-point zone located on the lower contact surface of the tool. Material used for coating the tool is aluminum sheet $2 \mathrm{~mm}$ thick, the usual quality for this purpose. The model of the workpiece is axisymmetrical, whose structure is formed with cross-laid sheets of peeled beech veneer with thickness of $1.5 \mathrm{~mm}$, while the bottom-contact list has a vertically oriented fibers in relation to the direction of motion over the contact surface of the tool. Experimental measurements are performed in realistic conditions of production in order to determine the effect of friction value, as one of the independent input parameters, on the output value of the pressing force.
\end{abstract}

Keywords: experimental measurements, friction, aluminium sheet, beech veneer, axisymmetric workpiece

\section{INTRODUCTION}

It is well known that all phenomena in the machining process is characterized by a set of parameters that determine the state of the system in which the process takes place. Modern and intelligent machining systems (CNC, AC, FMS), information technologies and computer technologies are forcing a larger need for exact determining of processes and systems and to make it possible it is necessary to carry out continuous research of whole system as well as each parameter of manufacturing system.

Very often during the analysis and modelling of manufacturing process it is not possible to cover all important influent parameters, so in this case among other things it is well to know their values in order to properly include all those parameters that significantly determine the conditions of implementation of process. After proper selection and determination of relations between primary and secondary parameters of process can be expected more accurate results.

The fact that wood has anisotropic properties, in different directions, indicates the need of permanent research of its behaviour during manufacturing. This paper starts from the assumption that the friction forces, which occur on the contact surface between the workpiece and tool, are primary (input) parameters in the process of forming laminated wood and that they have significant influence on the value of pressing force as a secondary parameter of manufacturing process.

If, considering those properties and clearly defined terms of use, behaviour of friction is to be properly determined and in this case it is wood-aluminium friction, then the researchers will be able to make more precise analysis and the engineers in practice will get a reliable basis for quality processing. The literature nowadays present a very different coefficients of friction of wood-metal and authors mostly do not specify the types of wood and metal they relate and in some specific cases they are only taken into account and in some cases their influence on manufacturing process is not known.

In support of this, we have carried out experimental measurements of friction forces, which appear as a result of resistance to movement of beech veneer on curved contact surface of tool during machining of axisymmetric workpieces of laminated wood. Experimental measurements are carried out in a real machining conditions with a goal to determine real values of friction force as one of the influent input parameter in a relation to output value of pressing force.

\section{THE METHODOLOGY OF PAPER}

For experimental research it was designed axisymmetric workpiece, shape as in Figures 1,2 and 3, with dimensions: $r_{n}=253[\mathrm{~mm}], b_{n}=450[\mathrm{~mm}], H_{0}=16,5$ $[\mathrm{mm}], \breve{\mathrm{s}}_{\mathrm{o}}=500[\mathrm{~mm}]$.

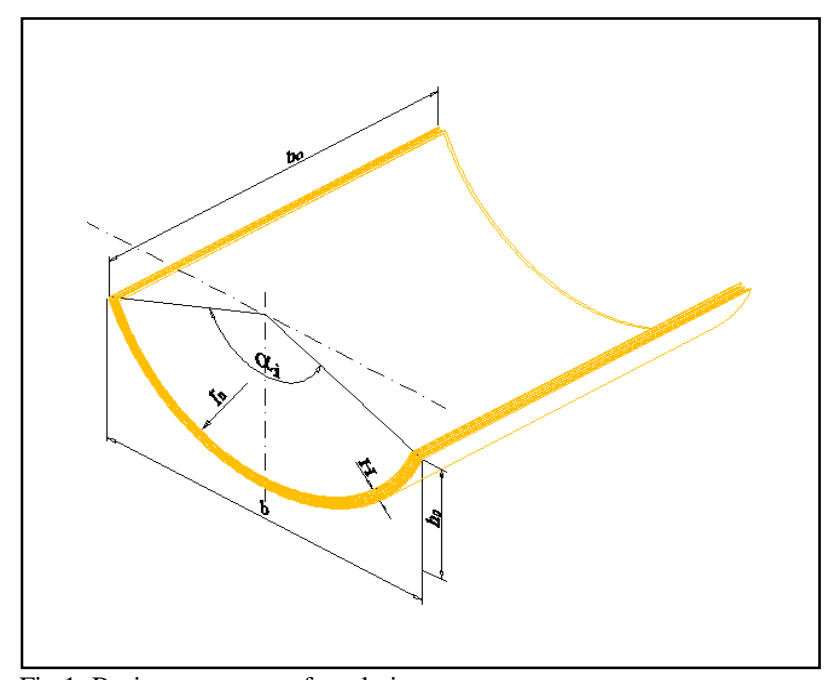

Fig.1. Basic parameters of workpiece 
Workpiece, with total thickness of 16.5 [mm] is formed with 10 lamella of beech veneer thickness of 1.5 [mm] and one with average thickness of 0.7 [mm]. Lower lamella has got vertical oriented fibers in relation to the direction of movement over the contact surface of tool. Forming tool (Figure 3) was designed on basis of structural parameters of the workpiece, made of laminated wood panels, stiffened with transverse screws and metal frames and contact surfaces are covered with aluminium sheet (anode and cathode) thickness of 2 $[\mathrm{mm}]$.

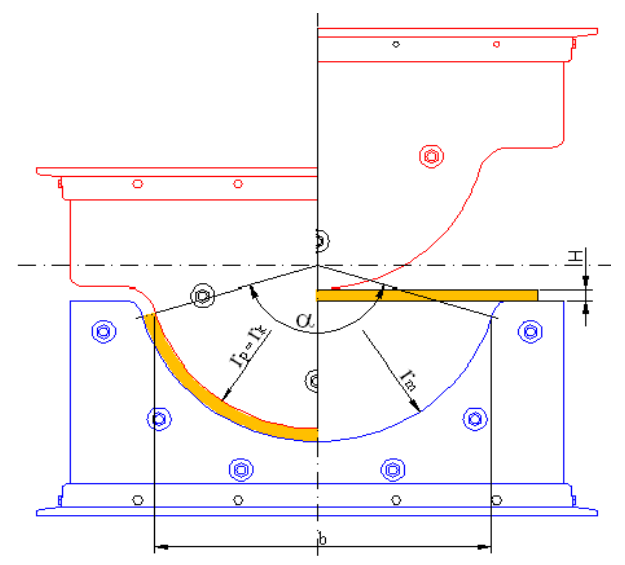

Fig.2. Basic model of tool and workpiece

Precision machining of basis surfaces of tool is made on CNC milling machine and other details are made in accordance with standards for this type of designing so that in all it fits in regular manufacturing. Same tool is after that set for experimental tests with additional reinforcement including bracket of measuring instruments, by which the instruments can be properly positioned in measuring points, Figure 4 and 5. After that the workpiece is loaded with expected load to test material rigidity.

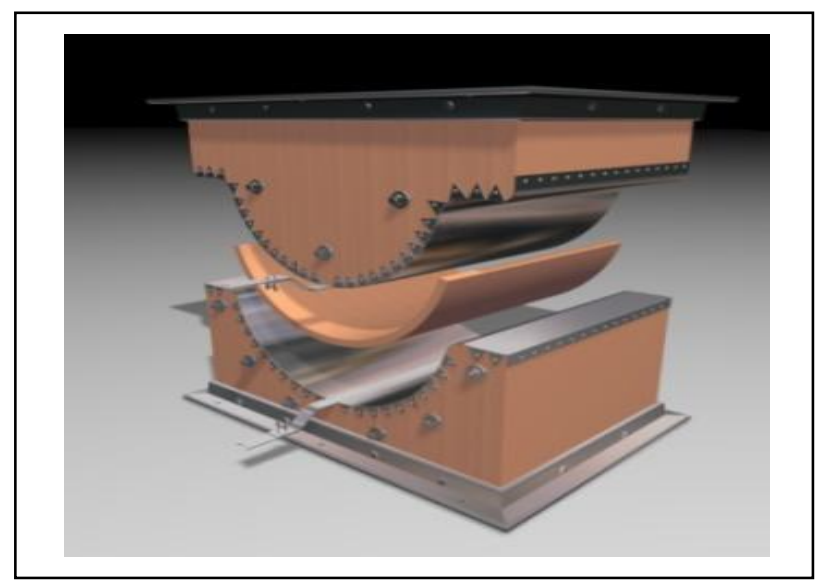

Fig. 3. 3D solid model of tool and workpiece

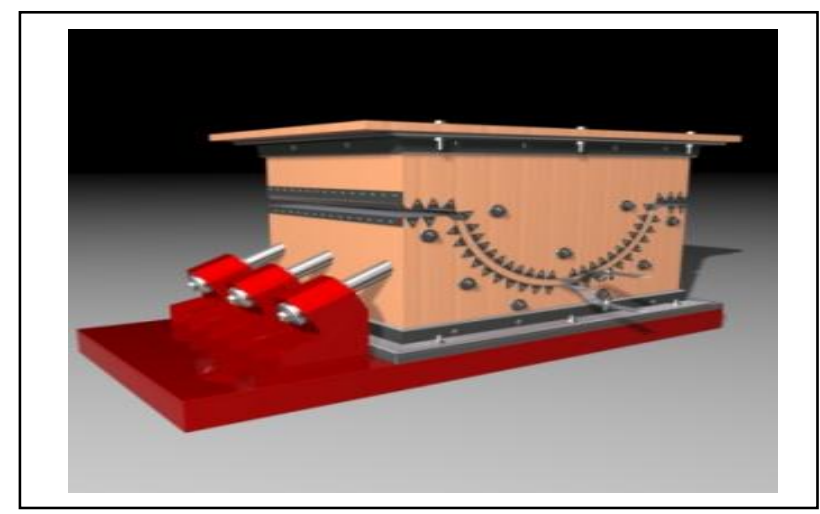

Fig. 4. Tool for experimental measurements

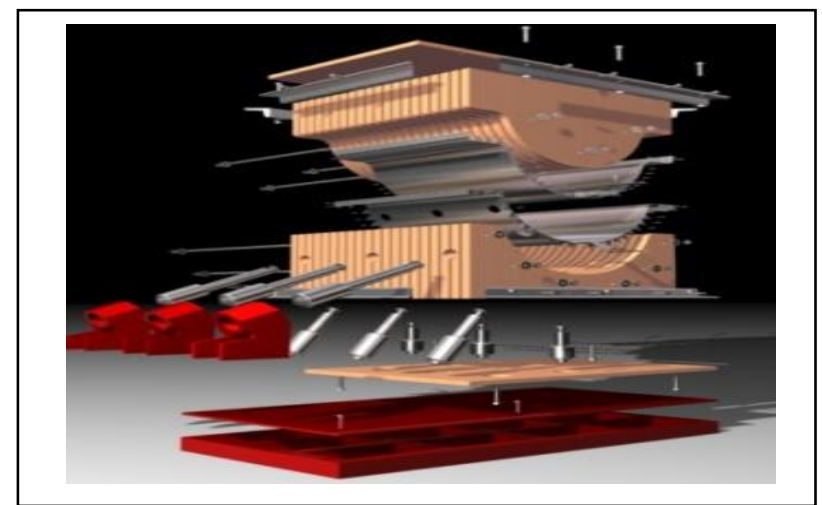

Fig. 5. Tool for experimental measurements and position of tool holder

During experimental research axial pressing force was measured as output variable parameter. For this case we have used strain gauge dynamometer, Figure 6., positioned in four symmetric points above upper part of tool, Figure 7.

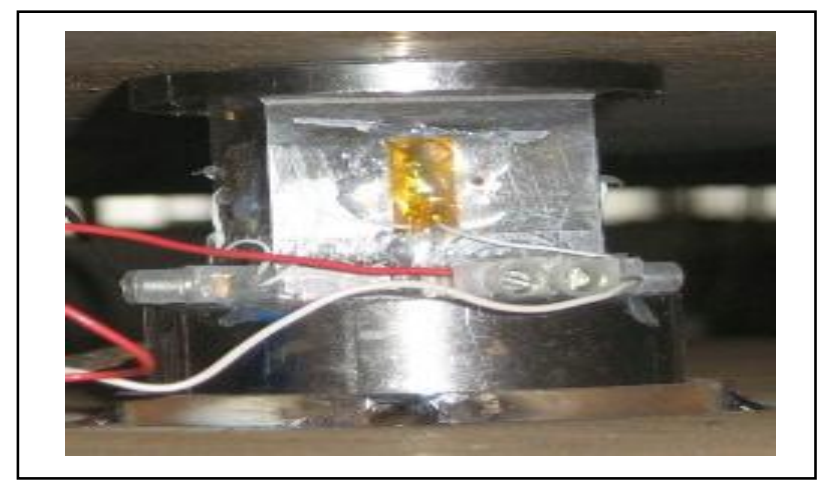

Fig. 6. Strain gauge dynamometer

Friction forces appear as a resistance of veneer movement over the curved lower contact surface of tool during machining, Figure 9. To measure the force in points $\mathrm{A}, \mathrm{B}$ and $\mathrm{C}$ there has also been used strain gauge dynamometer and its position is presented in Figure 8. To the upper part of tangential force sensor are placed bakelite plates, dimensions $\varnothing 37 \times 10[\mathrm{~mm}]$ as a insulator and above them are placed aluminium sheet plates the same one which are placed over the contact surface of tool. 




Fig. 7. Position of strain gauge dynamometer for measuring of axial pressing force

Both of these plates, together with upper disc of sensor are connected so that between them is no traction, which allows the transfer of tangential stress from contact surface to the sensor body on which are positioned tensometrical strips which are registering tangential force, Figure 9.

Contact surface of friction force sensor have got same radius as contact surface of tool matrix and through their middle points are passing tangents drawn perpendicular to the longitudinal axis of the sensor. Strain gauge dynamometers for measuring of friction force are brought to the points $\mathrm{A}, \mathrm{B}$ and $\mathrm{C}$ with sensor bracket which on the upper side has got bearing for sensors and on the lower side screw and nut which allows axial movement closer to or away from the workpiece, Figure 8.

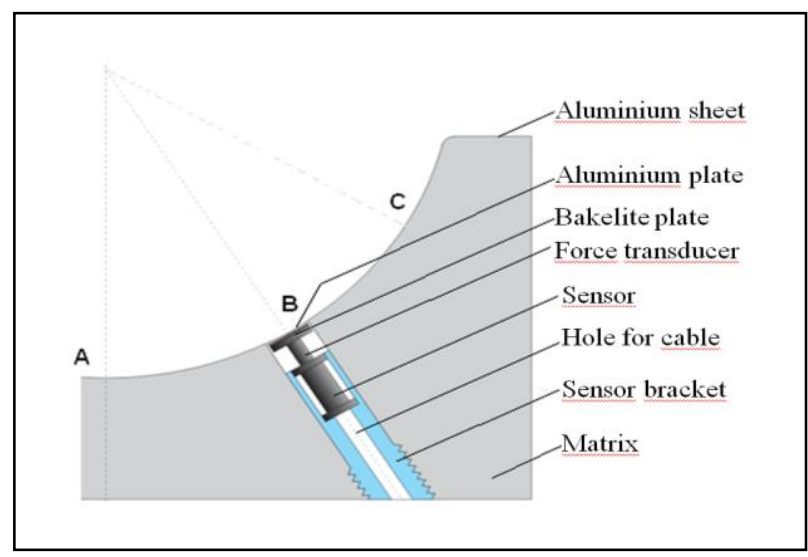

Fig. 8. Measuring points and sensor

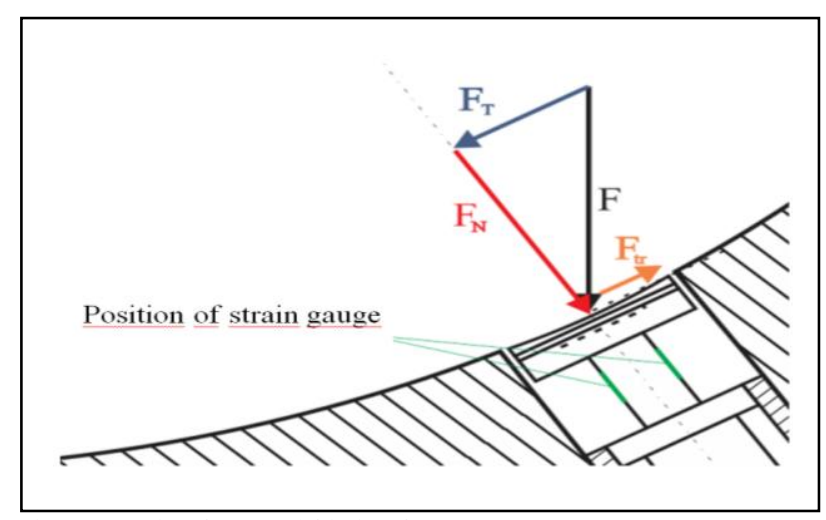

Fig. 9. Pressing force and friction force
For signal reception we have used measuring device Spider 8, Figure 10, manufacturer Metra Mess Technik, which have got possibility to measure on eight channels. Press that was used was Italpresse, type PHF-100 and HF generator, Figure 11.

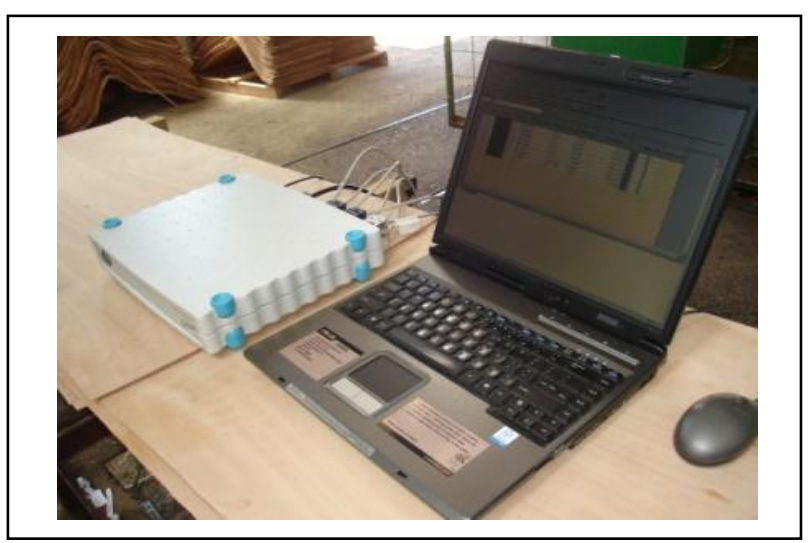

Fig. 10. SPIDER 8 and computer

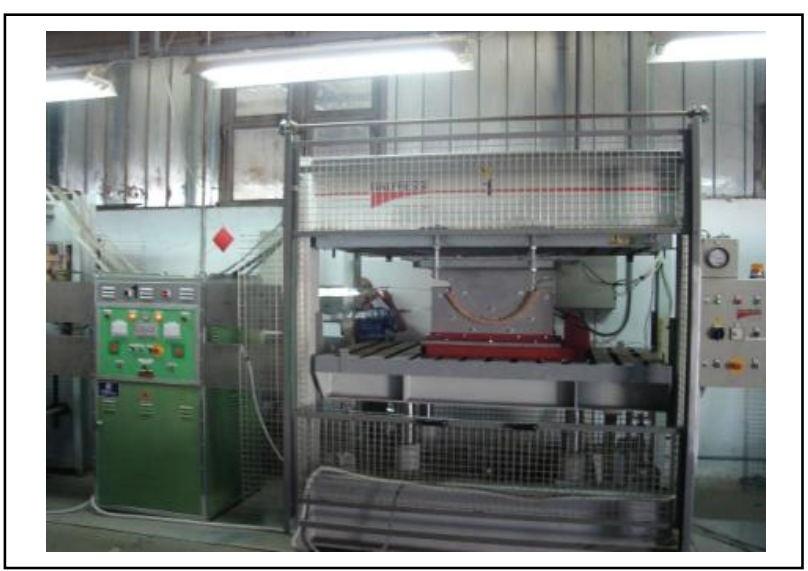

Fig. 11. Press machine and HF generator

Experimental measurements were performed in real process conditions of machining of axisymmetric workpieces of laminated wood by bending and bonding of wood with simultaneous heating with HF generator.

\section{RESULTS}

Results are presented for each experiment according to matrix plan and for each measuring point in Table 1.

\begin{tabular}{|c|c|c|c|c|}
\hline $\begin{array}{c}\text { Nr. of } \\
\text { exp. }\end{array}$ & $\begin{array}{c}\text { Pressing } \\
\text { force } \\
\text { Fp }\end{array}$ & $\begin{array}{c}\text { Friction } \\
\text { force } \mathbf{F}_{\mathbf{t A}}\end{array}$ & $\begin{array}{c}\text { Friction } \\
\text { force } \mathbf{F}_{\mathbf{t B}}\end{array}$ & $\begin{array}{c}\text { Friction } \\
\text { force } \mathbf{F}_{\mathbf{t C}}\end{array}$ \\
\hline E1 & $\mathbf{( k N )}$ & $\mathbf{( N )}$ & $\mathbf{( N )}$ & $\mathbf{( N )}$ \\
\hline E2 & 364 & 0,5 & 130 & 191 \\
\hline E3 & 261 & 0 & 244 & 327 \\
\hline E4 & 275 & 0 & 133 & 254 \\
\hline E5 & 262 & 0 & 166 & 127 \\
\hline E6 & 303 & 0 & 133 & 183 \\
\hline E7 & 260 & 0 & 362 & 168 \\
\hline E8 & 274 & 0 & 181 & 120 \\
\hline E9 & 281 & 0 & 252 & 235 \\
\hline E10 & 278 & 0 & 115 & 149 \\
\hline E11 & 278 & 0 & 115 & 165 \\
\hline E12 & 282 & 0 & 289 & 273 \\
\hline E13 & 282 & $-0,5$ & 133 & 86 \\
\hline & & & & \\
\hline
\end{tabular}




\begin{tabular}{|l|l|l|l|l|}
\hline E14 & 277 & 0 & 447 & 231 \\
\hline E15 & 254 & 0 & 204 & 124 \\
\hline E16 & 299 & 0 & 101 & 143 \\
\hline E17 & 290 & 0 & 267 & 176 \\
\hline E18 & 260 & 0 & 170 & 253 \\
\hline E19 & 278 & 0 & 124 & 113 \\
\hline E20 & 273 & $-0,39$ & 362 & 178 \\
\hline
\end{tabular}

Tab. 1. Results of experimental research

\section{ANALYSIS OF RESULTS}

The research results were obtained for the case of axisymmetrical workpiece, Figure 1 and 3 , which structure is formed by cross pointed sheets of beech veneer where external lower contact sheet has got fibers perpendicular oriented to the movement direction.

From the Table 1 it is evident that there are large discrepancies in the friction force values and its often increase and dicrease is not only due to increase or dicrease of pressing force value. The reasons for this are to be found in a wood as an anisotropic material, then the change of wood moisture which the wood absorbs from the glue, uneven distribution of pressure over the workpiece surface (due to its form and possible differences in thickness), temperature (due to water vapor, pressure increase, dilatation on the tool, workpiece, sensors).

The difference between the average values of measured friction force at points $\mathrm{B}$ and $\mathrm{C}$ is approximately $12 \%$ by the average measured pressing force $\mathrm{F}_{\mathrm{pr}}=276,75 \mathrm{kN}$.

\section{CONCLUSIONS}

According to the results presented in Table 1 we can conclude:

- measured friction forces in point A are zero which is expected. Negligibly small shifts in the experiments E1, E13 and E20, which sensor has registered, are assumed to be more due to the difference in the thickness of veneer, motion of glue, due to which there is a small movement of contact surface from side to side.

- average value of measured friction forces in point B is larger then average value of measured friction forces in point $\mathrm{C}$ which is logical because the normal stress in point B is larger.

- values of measured friction forces in some experiments are equal to the numerical results obtained according to the values of pressing force, but in some experiments values significantly deviates which can be due to the anisotropic characteristics of wood, moisture and temperature.

- possible reasons for the discrepancy of the measured friction and pressing force (experiment E7, E14, E17 and E20) in points B and C are higher pressure on the ends and middle of workpiece which occurs as a result of unequal relative pressing more in the middle zone and less on the ends), different thickness of the workpiece, spreading of glue from the center of workpiece to the ends, increase of pressure, heating of wood, moisture evaporation etc.

- results of experimental measurements described in this paper will serve as a real part in the forthcoming research in the area of numerical analysis, simulation and mathematical modeling of pressing force in process of design of axisymmetric pieces of wood.

\section{REFERENCES}

[1] Jurković, M. (1999) Mathematical modeling of engineering processes and systems (Matematičko modeliranje inženjerskih procesa $i$ sistema), Faculty of Mechanical Engineering Bihać, ISBN 9958-624-04-4, Bihać

[2] Hubka, V. (1976) Theory of Construction Processes (Teorie der Konstruktionsprozesse), Springer Verlag, Berlin/Heidelberg

[3] Zakić ,B. D. (1999) Mechanics of wood (Mehanika drveta), SANU, Beograd

[4] Shu, J.; Watson, L.T.; Zombori, G.B.; Kamke, F.A. WBC Sim: An Environment for Modelling Wood-Based Composites Manufacture, Departments for Computer Science and Mathematics and Department of Wood Science and Forest Products, Virginia Polytechnic Institute and State University, Blacksburg, USA

[5] Clouston, P.L.; Lam, F. Computational Modelling of StrandBased Wood Composites, Journal of Engineering Mechanics, August 2001, Pages 844-851

[6] Inoue, M.; Norimoto, M.; Thanahashi, M.; Rowel, R.M. Steam of Heat Fixation of Compressed Wood, Wood end Fibre Sci., 25(3), 224-235.1998

[7] Yadama, V. Characterization and Modeling of Oriented Strand Composites, Washington State University, Department of Civil and Environmental Enginnering, Decembar 2002, PhD Dissertation

[8] Nezirević, E. Contribution of Computer Modelling and Design of Tools for Bending Details of Furniture, Master Thesis, Faculty of Technical Engineering Bihac, 2008 